\title{
BASE: a sustainable path for the University of Milano-Bicocca
}

\author{
Cristina Messa ${ }^{1, *}$, Giacomo Magatti ${ }^{2}$, Massimiliano Rossetti ${ }^{2}$ Matteo Colleoni ${ }^{2}$ Massimo Labra $^{2}$, and Marina Camatini $^{2}$ \\ ${ }^{1}$ Rector, Milano-Bicocca University, Piazza dell'Ateneo Nuovo 1, 20126, Milano, Italy \\ ${ }^{2}$ BASE Bicocca Sustainability Office, Piazza della Scienza 1, 20126 Milano,
}

\begin{abstract}
Since its foundation, in 1998, the University of Milano-Bicocca has been pursuing the objective to make its structures sustainable from an environmental, social and economic point of view. To this end, in 2015 the University of Milano-Bicocca created BASE (Bicocca Ambiente Società Economia Bicocca Environment Society Economy), an internal office aimed at promoting the interaction between research and training and at stimulating sustainability both within the University and outside. BASE proposes a holistic approach to sustainability including energy efficiency, waste reduction, sustainable mobility, climate change attention and water and food supply. The report will focus on the interventions recently carried out in the various fields, paying particular attention to the issues of waste management and of mobility.
\end{abstract}

\section{Introduction}

Since its foundation, in 1998, the University of MilanoBicocca has been actively engaged in order to make its structures sustainable from an environmental, social and economic point of view. The objective has been pursued not only by reducing the environmental impact of its management but also by fostering sustainable behaviour among its employees and students. In 2015 the University of Milano-Bicocca created Bicocca Ambiente Società Economia - Bicocca Environment Society Economy (BASE), an internal office aimed at promoting the interaction between research and training and at stimulating sustainability both within the University and outside. Examples are the realization of studies and research on sustainability, training activities on the subject for students and staff and the coordination of the different sectors of the University in the implementation of measures for sustainability. Outside the University, BASE supports the attention towards sustainability by participating in working groups, locally (Bicocca district), nationally (University Network for Sustainable Development) and at international level (International Sustainable Campus Network - ISCN). BASE proposes a holistic approach to sustainability that includes the commitment to energy efficiency, waste reduction, sustainable mobility, climate change attention and water and food supply. After having presented the structure and the operating procedures of BASE, the report will focus on the interventions lately carried out in the various fields. Particular attention will be paid to the issues of waste and mobility management, which have been widely appreciated both at national and international level.

\section{BASE: a sustainable path for the University of Milano-Bicocca}

The universities play a key role in attaining the sustainable development goals set out in the $2030 \mathrm{UN}$ Agenda, firstly because it is the universities, above all, whose task it is to carry out studies and research into the environmental, social, and economic factors associated with sustainable development; secondly because it is in the Universities that students and staff are encouraged to adopt virtuous behavior to protect the environment and its resources; and lastly because the universities can play an important role in promoting collaboration on sustainability issues between public and private institutions and neighborhood associations [3].

That is why ever since it was founded, the University of Milano-Bicocca has been committed to the objective of sustainability. When it was being built, it was dedicated great attention to the environmental quality of the buildings, including the open and closed spaces, this commitment continued by creating BASE (Bicocca Environment, Society, and Economy), an interdepartmental and inter-disciplinary office under the Directorate-General of the University. The BASE Office is coordinated by a president assisted by a Scientific Committee consisting of 9 professors from different university Departments and has the role of providing scientific guidance and supervision for action on sustainability. The Scientific Committee is supported by two technicians who work in collaboration with the university's Infrastructure, Procurement and Communication Area to harmonize the scientific and operational aspects. In fact, it is a particular feature of BASE that it addresses sustainability across the 
disciplinary areas of the university and their research, training and management sectors. In that sense, sustainability is both an object of study and research for teachers and researchers, and a management goal for the university administrators. Finally, the external activities of Milano-Bicocca to promote sustainability is shown by its participation in local, national, and international working groups (Bicocca District, the Network of Universities for Sustainable Development, and ISCN, the International Sustainable Campus Network).

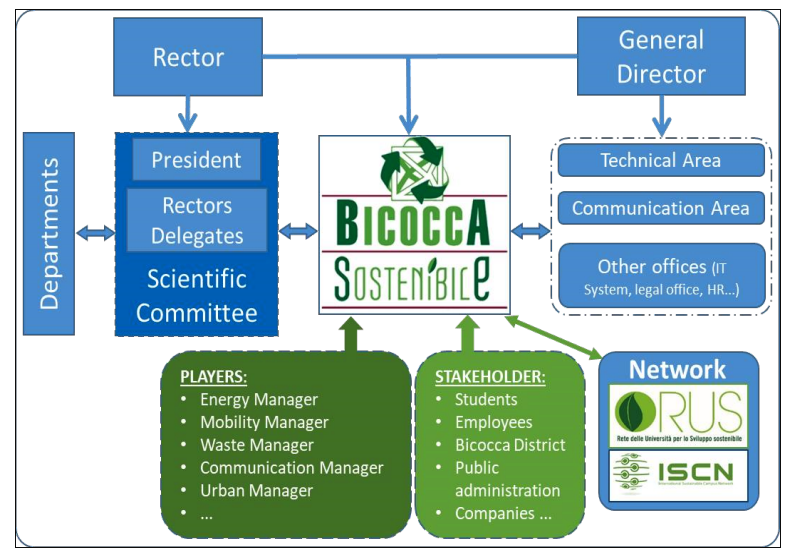

Fig. 1. BASE organizational diagram

In operational terms, the academic sustainability policies and interventions of Milano-Bicocca are planned within the framework of the Three-year University Environmental Sustainability Plan, which sets out the medium-term objectives and action to be taken to reduce pollutant emissions and energy consumption, promote sustainable mobility, reduce the production of waste, safeguard the quality of water and food resources, and protect the social categories that are most exposed to the negative consequences of the unequal distribution of resources (environmental, economic, and social, see Fig. 2) $[4]$.

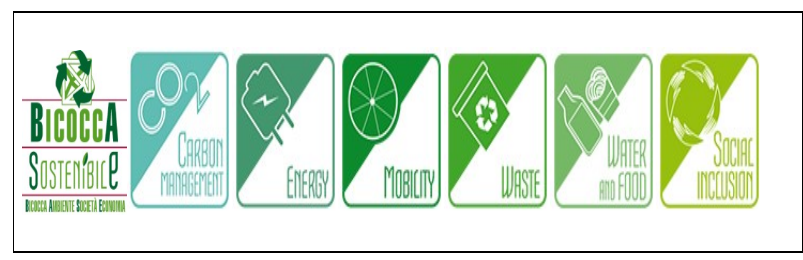

Fig. 2. Logos of the Milano-Bicocca University "sustainable path actions"

Within that context, BASE promotes a holistic approach to sustainability as both the goal and the outcome of joint effort by the different disciplinary areas and sectors of the university and the different actors in the surrounding territory, within a plurality of fields for intervention (environmental, economic, and social). The following section focuses on the two areas where Milano-Bicocca has attained its best outcomes and awards, nationally and internationally: waste management and mobility.

\section{Waste management at the University of Milano-Bicocca}

For many years the collection, management, and disposal of city waste within our University was addressed inefficiently and ineffectively and there was no standard method for managing the collection and disposal of waste across all the different buildings. Monitoring carried out during 2015 showed that $27 \%$ of that waste was being collected and disposed of differentially. Consequently, given that the amount of undifferentiated waste is an estimated 331 tons per year, the environmental impact of disposing of that waste was very high: 105 tons of $\mathrm{CO}_{2} \mathrm{e} /$ year (calculated in accordance with the Italian Ministry of the Environment's Guidelines for the Carbon Management of Universities on the undifferentiated proportion of waste). In fact, due to the need for it to be transported to the waste-to energy plant and incinerated, every ton of undifferentiated waste was responsible for producing $315 \mathrm{~kg}$ of $\mathrm{CO}_{2} \mathrm{e}$.

To reduce such a negative effect, a new waste management system was tested in 2016. In a first phase, all bins for undifferentiated waste were removed from all the offices and laboratories in the 28 university buildings and replaced with a paper waste collector only (as most of the waste is paper). Having studied the use of shared spaces in university buildings, approximately 500 islands for differentiated collection were installed at locations with the greatest potential for producing waste. As a consequence, the rate of differentiated waste collection increased from $27 \%$ to $70 \%$ (of which $50 \%$ was paper, $16 \%$ plastic and metal, and $4 \%$ glass), with a reduction of $45 \%$ in greenhouse gas emissions.

To comply with municipal standards, the containers on the islands were colored differently depending on the type of waste they were to contain (yellow for plastic and metal, white for paper, green for glass, and grey for undifferentiated waste, see Fig. 3), and these proved easy to identify and use. A preliminary communication campaign, giving clear information about the purpose of the new waste disposal system and how to use it, also contributed to the success of this initiative.

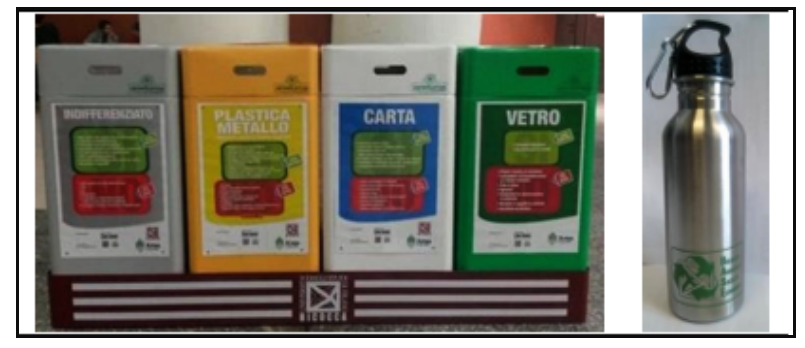

Fig.3. Left: an "Island" for differentiated waste collection at the University of Milano-Bicocca; Right: a BASE water flask

An integral part of this new waste management system was "PolApp", an application for smartphones and tablets that enabled users to monitor the islands and report back on the quantity and quality of differentiated waste that was being collected. Each island was identified by a Qr code, making it possible for University 
users to detect and send information on how full the containers were, and whether there were any problems, which enabled them to keep the management of the system under control. It also enabled them to compile thematic maps of the quantity and quality of waste being produced in the various buildings of the university.

The second phase of this new waste management system was aimed at reducing the need to collect and dispose of the plastic water bottles dispensed from machines or sold in university cafeterias and bars. For that purpose, 13 water dispensers were installed in the university buildings, and over this past year they have supplied, free of charge, approximately 250,000 liters of natural and sparkling drinking water (enabling a saving of about $18,200 \mathrm{~kg}$ of CO2 emissions per year). Finally, the free distribution of steel flasks, marked with the BASE logo, to the university students and staff has achieved the twofold result of limiting the use of plastic bottles whilst at the same time identifying these ecological flasks as the symbol of this new community of environmentally sustainable and responsible consumers.

\section{Sustainable mobility management at the University of Milano-Bicocca}

Since 1998 all public institutions and private companies in Italy with more than 300 employees in a single location (or with more than 800 employees in multiple locations, according to the interministerial decree "Sustainable mobility in urban areas" - Legislative Decree 27/03/1998) must appoint a Mobility Manager tasked with:

- encouraging greater use of sustainable modes of transport;

- improving sustainable access for persons and organizations;

- increasing the efficient use of transport infrastructure and types of land use;

- reducing traffic by reducing the number and length of journeys and the use of private vehicles.

As public institutions, all Italian universities have Mobility Managers who are organized under a National Coordination and are committed to making the journeys of university students, academics, and administrative staff more sustainable. Like other Mobility Managers, the university Mobility Managers are required to draw up a home/work/university travel plan, to participate in the governance of urban and metropolitan mobility, and to carry out studies and research on university mobility. In 2017 the National Coordinator of University Mobility Managers, working under the direction of the University of Milano-Bicocca's Mobility Manager, prof. Matteo Colleoni, carried out the first national survey on travel and shared mobility in the Italian universities (based on a sample of 37 universities and approximately 70,000 cases).

This was the first survey carried out in Italy using a common data collection tool, and showed that the different modes of travel were well distributed (with
$61 \%$ of the respondents making their home/university journeys using public transport) and that there was a positive tendency to share journeys, although the negative aspects included a poor take-up of active mobility (on foot and by bicycle), the time taken by these journeys and their high costs. This last consideration was seen as a cause for concern, since it limits the opportunities for students to access and attend their university and has a negative impact on their entitlement to study. Furthermore, although students and staff make most of their journeys by public transport, these generate greenhouse gas emissions of approximately 31,480 tons of $\mathrm{CO}_{2} \mathrm{e} /$ year (or $64 \%$ of the entire university carbon footprint, the remainder consisting of emissions associated with energy generation, $35 \%$, and waste disposal, 1\%).

To address these issues, the mobility management policies of the University of Milano-Bicocca were divided into different sectors of activity aimed at:

- increasing active mobility;

- improving the quality of public transport and the intermodality of the transport system; - increasing the types of shared mobility.

In relation to active mobility, a bike sharing service is currently being completed that will support the oncampus mobility of university staff. The bicycles are fitted with smart locks, are owned by the university and the municipality, and will be supported by a digital platform (APP and web app) that will make the bicycles easier to hire, collect, and return. In relation to pedestrian movement, the university is supporting the Municipality of Milan in making critical road crossings safe and creating cycling/walking routes that encourage active mobility. Since 2016, the University of Milano-Bicocca has been participating in the European "Bike2Work smart choice for commuters" campaign, which will use innovative incentive schemes (based on economic and time rewards and benefits) to shift journeys away from private cars towards cycling.

As it has been mentioned, public transport is the predominant mode of travel by Italian university students, specifically by those attending Milano-Bicocca (with public transport usage rates of $80 \%$ ). Mobility management policies in that mode are therefore aimed at improving the quality of travel on public transport and increasing the intermodality of the transport system (particularly the use of integrated journeys that combine bicycles and public transport). So far as the quality of public transport is concerned, great attention has been paid to convention agreements with the transport companies that improve public transport and make it fairer and cheaper to use. Employees who purchase tickets for use on public transport (bus, metro and train) receive a financial contribution from the university that covers approximately $30 \%$ of the cost. However, since the University cannot afford to pay the subsidy to the very large number of students who live outside the regional capital, those students do not receive that discount. Nevertheless, the University of MilanoBicocca is currently coordinating negotiations with Trenord, the regional railway company, and the other 
universities of the region to find an agreement that will also make it cheaper for those students to buy travel tickets. Finally, an agreement between the University of Milano-Bicocca and Trenitalia, the national rail operator, which is already in operation, gives university employees and students a $15 \%$ discount on trains. The underlying aim of that agreement, and of the others mentioned, is to provide financial support for mobility in the conviction that making travel easy improves working conditions and, consequently, the productivity of Italian university students in their various disciplines. The railway companies would benefit from the increasing number of clients using public transport with lower levels of pollution.

Lastly, the adoption of shared mobility has been spreading rapidly over the past few years in Italy, particularly in Milan. New car and bicycle sharing and pooling services are expanding the range of modal choices and increasing the proportion of shared mobility, particularly within the urban area. On the campus itself, the University of Milano-Bicocca provides a free lowenvironmental-impact bus service and gives discounts for bus and van sharing services, car-pooling, car + scooter travel, and cycle hire. Every year there is a Bicocca Mobility Day, which provides an opportunity to present the mobility support services to students and staff and to meet with the other local and regional stakeholders and discuss policies for improving sustainable university travel. The underlying objective of these and other initiatives is to transform shared travel from a simple choice of mode to a style of mobility and a way of using the city, and to encourage behaviour that fits well with the principle of sharing resources and being attentive to the well-being of the community and the present and future environment.

To sum up, the University of Milano-Bicocca is aware of the negative effects that the transport sector has on environmental quality and climate change and is devoting great effort and resources to the implementation of sustainable mobility policies. Many years of academic travel management policies have shown that the universities, which were traditionally considered as mere attractors of mobility, can and must actively participate in planning and programming urban and metropolitan policies to achieve a type of mobility that is ever more attentive to the sustainability of the environment [1].

\section{Summary/ concluding remarks}

20,000 teachers and employees and more than 200,000 students work or study at the five universities in the city of Milan, $40 \%$ of whom make a daily journey to get there and back. At Milano-Bicocca alone, about 15,000 students and staff need to access and use the university's resources. These high numbers put great pressure on the resources of the university and its environment, requiring the adoption of policies to safeguard its conservation and regeneration. As part of the Italian network for sustainable development, Milano-Bicocca has been implementing these policies by entrusting BASE with the task of addressing the issue in a multi-disciplinary, multi-sectoral way, paying attention to sustainability in its various different aspects. Twenty years since MilanoBicocca was first set up, it can be said that these policies have been delivering positive outcomes, especially in particular areas such as waste management and mobility. Positive signals are also coming from other sectors such as energy saving, reducing emissions from pollutants, and policies for social inclusion. None of these results would have been possible without collaboration between the scientific and administrative components of the university, and external exchanges with other universities also belonging to the national and international network for sustainable development: demonstrating that as in the natural world, action on sustainability gives the best local results when it is shared and constructed collectively [2].

Acknowledgements. The Rector of the University of MilanoBicocca and the Scientific Committee of BASE wish to thank the University Infrastructure and Procurement Area, particularly its Director Marco Cavallotti and the Engineer Dr. Marco Angelillis, for their support with the implementation of these environmental sustainability policies and the activation of BASE.

\section{References}

1. Colleoni M., Pucci P., Understanding Mobilities for Designing Contemporary Cities, Springer (2016)

2. Magatti G., Camatini M., et al., Energy Consumption Analysis and Carbon Footprint of a Building of the University of Milano-Bicocca: Starting Point for a Sustainability Report. Energia, Ambiente, Innovazione. ENEA (2013)

3. Ministry of the Environment and Protection of Land and Sea, - G.D. for Sustainable Development, Climate and Energy; University Cà Foscari of Venezia - Ufficio Processi e Progetti Speciali. Linee Guida in materia di Carbon Management per gli Atenei. Case study: Università Cà Foscari Venezia (2012)

4. Scientific Committee BASE, University Sustainable Environmental Plan - 3year-period 2017-2020, approved by the Administration Committee of the University of Milan-Bicocca, 2017/07/18 